\title{
The most famous fish: human relationships with fish as inferred from the corpus of online English books (1800-2000)
}

\author{
Konstantinos I. Stergiou ${ }^{1,2, *}$ \\ ${ }^{1}$ Institute of Marine Biological Resources and Inland Waters, Hellenic Centre for Marine Research, Aghios Kosmas, \\ 16777 Athens, Greece \\ ${ }^{2}$ Laboratory of Ichthyology, Department of Zoology, School of Biology, Aristotle University of Thessaloniki, \\ UP Box 134, 54124 Thessaloniki, Greece
}

\begin{abstract}
Despite the historically close connection between humans and fish, the question 'What is the most famous fish species?' has never been asked. I used Google Ngram viewer to estimate the frequency of times the common names of 250 fishes appear in the corpus of digitized English books published between 1800 and 2000. I propose the 'famon' as a unit of fame, with 1 famon $=10^{-6}$ relative \% Ngram frequency. Twelve of the 250 common names are words which also have other uses in English and were thus not considered here, and 57 species had 0 famons. For the remaining 181 species, fame increased for 139 (76.8\%), during or part of 1800-2000. Goldfish Carassius auratus, the most common laboratory and aquarium fish and the second fish to be domesticated, is the most famous fish, reaching 80 to 117 famons after 1930. It was introduced to Europe from China about 325 to 450 yr ago and then to North America around 1850. Goldfish have penetrated into cultural aspects of human civilization (e.g. stamps, art, music). 'Goldfish' also appears in the corpus of simplified Chinese, French, German, Italian, and Spanish books. The results show the universality and dominance of goldfish in the digitized published heritage. This likely indicates that non-consumptive cultural aspects, including aesthetic, spiritual, and recreational components, play a central role in defining the relationship of humans with fish, being equally important as provisioning, regulating, and supporting services, and thus should be valued accordingly for conservation. However, cultural services have not yet been adequately integrated within the ecosystem service framework and are generally excluded from economic evaluations, a fact raising ethical issues with respect to their relative evaluation.
\end{abstract}

KEY WORDS: Fame · Famon · Goldfish · Carassius auratus · Darwin · Ecosystem services · Cultural services

\section{INTRODUCTION}

Fish play an important role in aquatic ecosystems, spanning trophic levels from 2, for purely herbivorous fish such as Siganus spp., up to 5, for predatory species such as bluefin tuna Thynnus thunnus, swordfish Xiphias gladius, and several species of sharks (Cortés 1999, Stergiou \& Karpouzi 2002, Froese \& Pauly 2015). Humans have historically had very strong bonds with fish and fishing, with both playing an important role

\footnotetext{
*Corresponding author: kstergio@bio.auth.gr
}

in ancient life and economy and thus in human wellbeing. This is very well illustrated by the fact that fish represented one of the 2 greatest passions of the ancient Athenians (Davidson 1997). Citing McEvoy (1986), Merchant (1997, p. 25) stated that 'Like the gold that had been discovered in California, fish were treated as gold nuggets, serving as the coin of trade.' Fish are an important, protein-rich, healthy food source (see Cunnane \& Crawford 2003 for the relation between fish diet and evolution of human brain

() The author 2017. Open Access under Creative Commons by Attribution Licence. Use, distribution and reproduction are unrestricted. Authors and original publication must be credited. 
size) with unique psychotropic properties (Reis \& Hibbeln 2006). Fish are also a cultural source of inspiration for artistic/pictorial representations (e.g. wall paintings and frescos, mosaics, sculptures, coins), with the Minoan fresco the 'Little Fisher from Thera' from Santorini Island (dated back to $\sim 3600 \mathrm{yr}$ ago) being the most famous (Stergiou 2005, 2011). Such a close relationship is depicted in the writings of ancient Greeks and Romans in specialized books on 'natural history' (e.g. 'History of Animals' by Aristotle [384-322 BC] and 'Naturalis Historia' by Pliny the Elder [23-79 AD], in which both describe various aspects of the life histories of fishes and other marine organisms), in books on fishing (e.g. a poem on fishing, entitled 'Halieutika,' by Oppianos of Cilicia [ $2^{\text {nd }}$ half of the $2^{\text {nd }}$ century]; Egerton 2001), in Greek tragedies (e.g. those of Aeschylus [ $4^{\text {th }}$ to $5^{\text {th }}$ century $\mathrm{BC}]$ ) and in other writings (e.g. 'Histories' by Polivios [203-120 BC], 'The Deipnosophists' by Athenaeus [ $2^{\text {nd }}$ to $3^{\text {rd }}$ century AC]; Stergiou 2011). In their review of the cultural symbolism of fish and the psychotropic properties of their omega-3 fatty acids, Reis \& Hibbeln (2006) maintained that fish have also been culturally considered as symbols of social healing and emotional well-being in religious and medical practices in different cultures, for at least $6000 \mathrm{yr}$. Fish are also among the 3 top favorite pets (together with dogs and cats) even topping the list (in terms of the number of households with fish as pets) in some countries (e.g. Italy; https://en.wikipedia.org/wiki/Pet\#Pet_ popularity). The strong relationship between humans and fish is also indicated by recent, popular books such as Kurlansky's (1998) 'Cod: a biography of the fish that changed the world' and the New York Times best seller 'Four fish' by Greenberg (2010). The important role of fish for humans becomes clear when one considers that out of the 33200 currently recognized fish species (Froese \& Pauly 2015) about onethird are used by humans as food, in the fishmeal industry, for bait, in aquaculture, in recreational and subsistence fishing, and in the aquarium trade.

The relationship between humans and other animals, including fish, is very important because it largely determines how humans will interact with them (Kudo \& Macer 1999), and there is deep and diverse philosophical thinking on the moral status of animals with which we share our lives (Gruen 2014, and see www.iep.utm.edu/anim-eth/\#H4) as well as for the management of their populations (Merchant 1997). In fact, despite the close relationship between humans and fish, the latter generally do not enjoy a level of compassion similar to that enjoyed by 'warmblooded' vertebrates (Brown 2015).
Given the close relationship between humans and fish, it is no surprise that the latter attract a lot of media attention because of the alarmingly poor status of their stocks (e.g. Pauly et al. 1998, Vasilakopoulos et al. 2014), their occasional extremely high market prices (e.g. bluefin tuna), when very largesized or rare fish species are accidentally caught and landed, and in the case of shark attacks. Yet, despite such a historically close connection between humans and fish, the question of which fish species is the most famous has never been asked or answered. The answer to this question will cast light on which factors (i.e. cultural, aesthetic, economic, recreational, subsistence) play a role and eventually define the relationship of humans with other organisms, in this case fish, and thus should be considered when evaluating different ecosystem services. This might have ethical implications given that these factors are not all considered to be of equal importance when evaluating ecosystem services.

Fame, or reputation (i.e. what is said or reported about a name), can be objectively quantified by estimating the frequency with which the name of an entity appears in various sources such as books (Michel et al. 2011). Michel et al. (2011) constructed a corpus of digitized books, developed a computational tool (Google Ngram viewer; later expanded by Lin et al. 2012), which estimates the percentage of times a word (or a phrase) appears in the corpus of books, and investigated its usefulness in social sciences and humanities. Ngram has been successfully used in many fields of knowledge, from linguistics, literature, accounting, computer and environmental sciences, to ethics and estimating university reputation rankings (Table 1). This shows the importance of the digitized availability of the millions of books online as well as of Michel et al.'s (2011) tool for all sciences and the humanities.

Here I used Ngram to investigate patterns in the use of the common names of 250 fish species in the corpus of digitized English books with the aim of identifying the most 'famous' fish in the modern, English-speaking world.

\section{MATERIALS AND METHODS}

Ngram is an online tool (http://books.google.com/ ngrams) that produces a graph in which the $y$-axis shows how many times a phrase occurs in a corpus of books (making up about $6 \%$ of all books ever printed; Lin et al. 2012) relative to all remaining phrases composed of the same number of words (i.e. relative frequency) during the same time ( $X$-axis). A 
Table 1. Applications and uses of Michel et al.'s (2011) Ngram tool in different disciplines

\begin{tabular}{|ll|}
\hline Application/use & Reference \\
\hline $\begin{array}{l}\text { Tracking poverty enlightenment } \\
\text { Tracking emotions in novels }\end{array}$ & Ravallion (2011) \\
& $\begin{array}{c}\text { Mohammad (2011), Acerbi } \\
\text { et al. (2013) }\end{array}$ \\
As a grammar checker & Nazar \& Renau (2012) \\
Studying the evolution of computing & Soper \& Turel (2012) \\
Studying the evolution of women's status & Twenge et al. (2012) \\
Accounting & Ahlawat \& Ahlawat (2013) \\
Poetry & Diller (2013) \\
Tracking pronoun use in books & Twenge et al. (2013) \\
Studying the evolution of novels & Egnal (2013) \\
Analyzing the drug research literature & Montagne \& Morgan (2013) \\
Estimating university reputation and rankings & Stergiou \& Tsikliras (2014) \\
Studying the evolution of trophic flows & Libralato et al. (2014) \\
Ethics & Pauly \& Stergiou (2014) \\
Studying the evolution of resource economics & Sumaila \& Stergiou (2015) \\
\hline
\end{tabular}

detailed account of the Ngram tool is given by Michel et al. (2011) and Lin et al. (2012), whereas an application guide is available online (http://books.google. com/ngrams/info\#advanced). The analysis is available for 1800-2008 but data are more consistent for 1800-2000 (Lin et al. 2012).

I used Ngram to estimate the relative frequency of appearance of the common names of different fish species in the corpus of English books published between 1800 and 2000. Herein I define and use the famon (Gr. fími, fame, from which L. fama, fame, is derived) as a unit of fame, with 1 famon $=10^{-6}$ relative \% Ngram frequency.

Currently, 33200 fish species are recognized (Froese \& Pauly 2015). Since it is not possible to check the relative frequencies of all 33200 species in the online books, I used a subset (see Tables S1 \& S2 in the Supplement at www.int-res.com/articles/suppl/e017 p009_supp.xls). Firstly, I checked the relative frequency of occurrence of the common names of the 100 most viewed species in FishBase and of the 50 most important marine game fish (Table S1). The latter were taken from 'Sport Fishing Magazine,' which constructed the list based on the suggestions of the 61 top anglers and skippers of the world. I further estimated the relative frequencies of the common names of all fish species with landings $>235000 t$ (for 2013) and of those farmed, both from the Food and Agriculture Organization (FAO), as well as of several other well-known 'top' fish species from various sources (Table S1). Finally, I checked the relative frequencies of 26 species randomly selected from FishBase (i.e. the first species that has a common name for each of the 26 letters of the English alphabet; Table S1).
For all sources providing only common names, I used only those that corresponded to one particular scientific name in FishBase. If the common name in the source differed from that in FishBase, then I checked for both common names in Ngram and used the one with the highest relative frequency. Overall, I checked 250 unique species, which cover the different uses of fish by humans (i.e. commercial fishing, fishmeal industry, aquaculture, game fishing, bait, aquarium trade). Common names were checked for other uses in the English language with the "* word' and 'word *' Ngram option.

Fame may be related to the age of an entity's name (e.g. for universities: Stergiou \& Tsikliras 2014). Thus, I also tested whether a relationship exists between the age of common names (i.e. 2015 minus the year of the first appearance of a common name in the books) and maximum fame for the 181 species which had frequencies $>0$ famons. Finally, one might hypothesize that the larger a fish is (i.e. more conspicuous or charismatic), the larger its fame will be. Thus, I also tested whether a relationship exists between maximum length, $L_{\max }$ (taken from Froese \& Pauly 2015), and fame for the 181 species with fame $>0$ famons.

\section{RESULTS}

Only 1 of the 250 species checked did not have a common name (Copadichromis azureus; top 100 FishBase species). Fame ranged between 0 famons (i.e. no Ngram frequencies for 1800-2000) for 57 species, to 117 famons for goldfish Carassius auratus. The common names of 7 species (flier Centrarchus macropterus, haddock Melanogrammus aeglefinus, meagre Argyrosomus regius, molly Poecilia sphenops, oscar Astronotus ocellatus, permit Trachinotus falcatus, and sturgeon Acipenser sturio) are words which also have other uses in the English language (e.g. person names, locations; Table S1). As a result, these common names attain fame levels as high as 4900 famons, depending on the common name (Table S2). For instance, haddock/Haddock exhibits a peak of 100 to 147 famons in 1922-1930 (Fig. 1). However, Haddock is also a common surname in English. Indeed, part of the 1922-1930 frequency peak is attributed to 'Mr. Haddock' and 'Mrs. Had- 


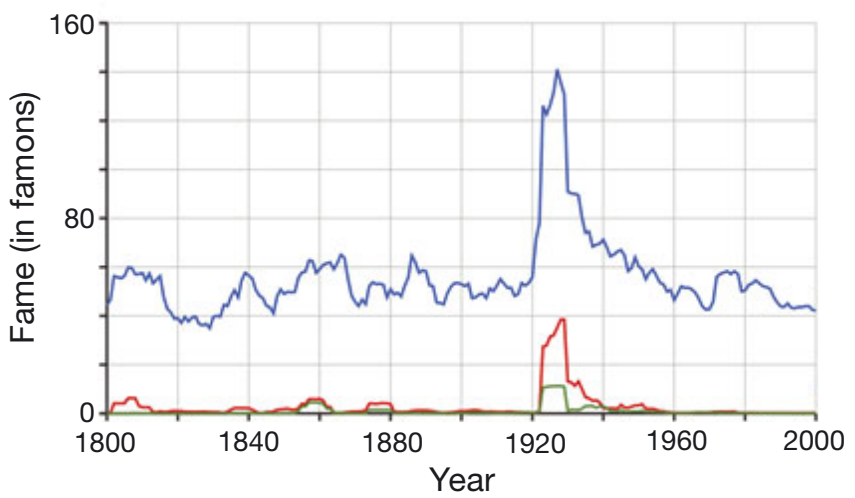

Fig. 1. Usage in famons ( 1 famon $=10^{-6}$ relative frequencies) of 'Haddock' (blue), 'Mr. Haddock' (red), and 'Mrs. Haddock' (green) in the corpus of English books published between 1800 and 2000

dock,' which together amount to about 50 famons (Fig. 1), whereas other names appearing in Ngram are 'admiral/Admiral Haddock,' 'Richard Haddock,' and 'Captain Haddock.' Thus, the above mentioned 7 species were excluded from the analyses. From the remaining 243 common names, which have frequencies $\leq 117$ famons, 5 species also have common names, which again have other uses in English (white cloud Tanichthys albonubes, morari Cabdio morar, bogue Boops boops, sergeant major Abudefduf saxatilis, beluga Huso huso; Tables S1 \& S2) and thus their records were also not considered here. Several other common names also have other uses in English, but the frequency of these uses was very low (Table S1).

Overall, 131 of the 238 English common names considered in the analysis have frequencies <1 famon (median 0.56). Of the 181 species having non0 values, fame exhibited an increasing long-term trend for 139 species $(76.8 \%)$, a declining trend for 8 species $(4.4 \%)$, and no trend or another type of trend for $18(9.9 \%)$ and 16 species $(8.8 \%)$, respectively, between 1800 and 2000 or part of this period (Table S2). For 124 of the 181 species $(68.5 \%)$, fame exhibited long-term cycles. For the study period (i.e. 1800$2000)$, almost $60 \%$ of the common names (108/181) appeared in the English books for the first time between 1800 and 1899 (Fig. 2).

Goldfish dominates the fame spectrum after 1920, being the most famous fish (Fig. 3). Its fame exhibited long-term cycles and reached levels generally higher than 80 famons between 1930 and 2000, with a maximum of 117 famons in the late 1980s (Fig. 3). Of the remaining species, among the most dominant ones in the fame spectrum were: (1) rainbow trout Oncorhynchus mykiss, reaching 60 to 80 famons between 1980 and 2000 (maximum in 1990; Fig. 3); (2) sea trout Salmo trutta, which generally domi-

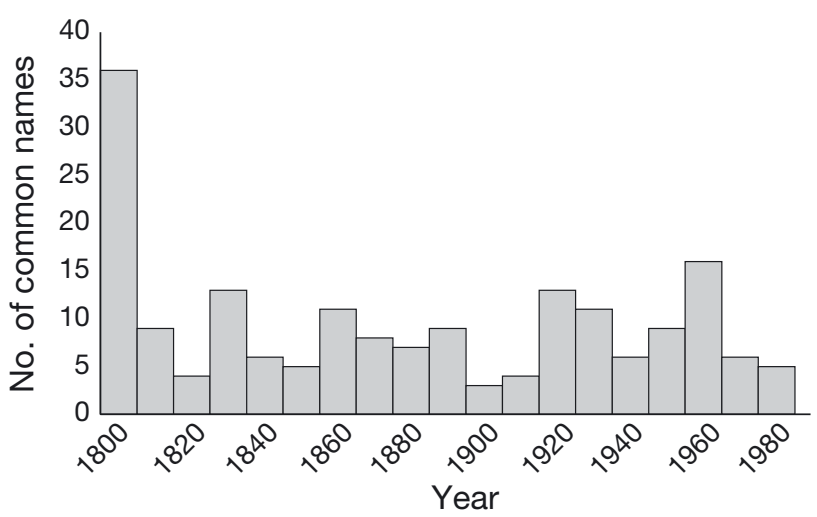

Fig. 2. First appearance of the common names of the fish species examined in Ngram published between 1800 and 2000

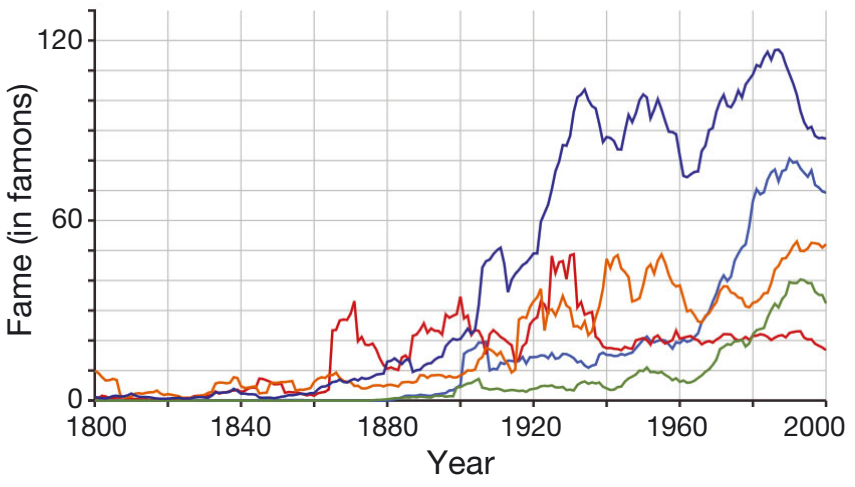

Fig. 3. Usage in famons ( 1 famon $=10^{-6}$ relative frequencies) of all forms of 'goldfish' (dark blue), 'rainbow trout' (light blue), 'swordfish' (orange), 'Atlantic salmon' (green), and 'guppy' (red) in the corpus of English books published between 1800 and 2000. For 'guppy,' part of the frequency between 1800 and 1920 is attributed to 'Mr. Guppy' and less so to 'Mrs. Guppy,' 'Henry Guppy,' 'B. Guppy,' and 'Dr. Guppy,' but these terms contribute verylittle after 1920

nated between 1800 and 1910, with frequencies as high as 50 famons, with a maximum of 53 famons in the late 1940s (Fig. 4); (3) swordfish Xiphias gladius, with 30 to 53 famons between 1980 and 2000 (Fig. 3); (4) guppy Poecilia reticulata, which peaked in 1865-1900 (maximum 35 famons) and 1920-1930 (maximum 48.7 famons) (Fig. 3); (5) Atlantic salmon Salmon salar with 20 to 40 famons between 1980 and 2000 (Fig. 3); and (6) striped bass Morone saxatilis, brook trout Salvelinus fontinalis, and walleye Sander vitreus, with 25 to 33 famons between 1980 and 2000 (Fig. 4). Four more examples are shown in Fig. 5, which shows 2 species for which fame declined with time (turbot Psetta maxima and sterlet Acipenser ruthenus) and 2 species (bluefish Pomatomus saltatrix and John Dory Zeus faber), for which fame displayed no trend. Turbot, in particular, had 


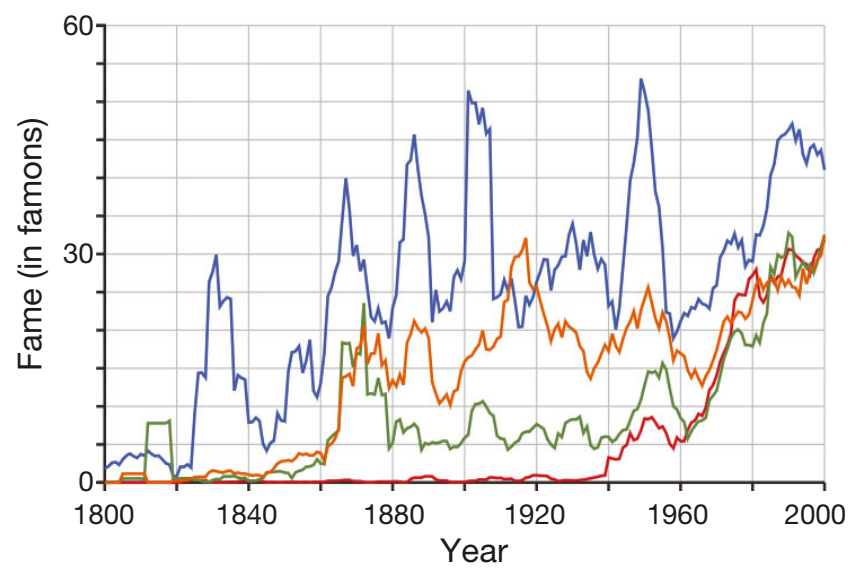

Fig. 4. Usage in famons ( $1 \mathrm{famon}=10^{-6}$ relative frequencies) of all forms of 'sea trout+brown trout' (blue), 'striped bass' (green), 'brook trout' (orange), and 'walleye' (red) in the corpus of English books published between 1800 and 2000

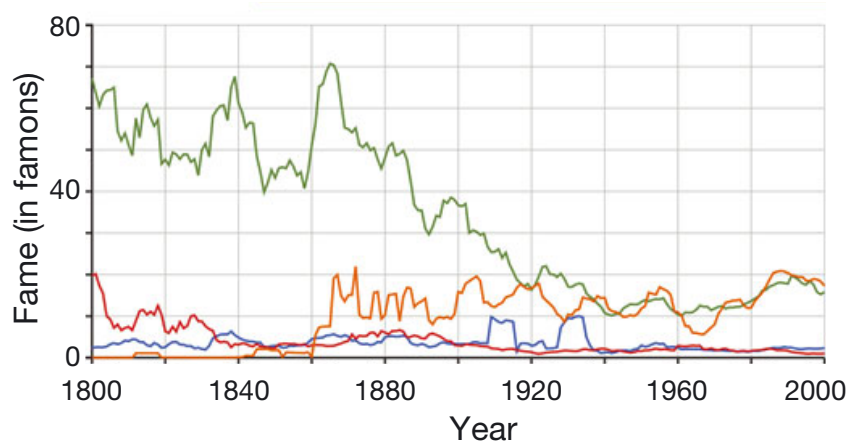

Fig. 5. Usage in famons ( $1 \mathrm{famon}=10^{-6}$ relative frequencies $)$ of all forms of 'turbot' (green), 'sterlet' (red), 'bluefish' (orange), and 'John Dory' (blue) in the corpus of English books published between 1800 and 2000. For 'turbot,' $<1$ famon is attributed to 'Turbot Francis' and very small frequencies to 'Mr. Turbot' and 'Timothy Turbot'

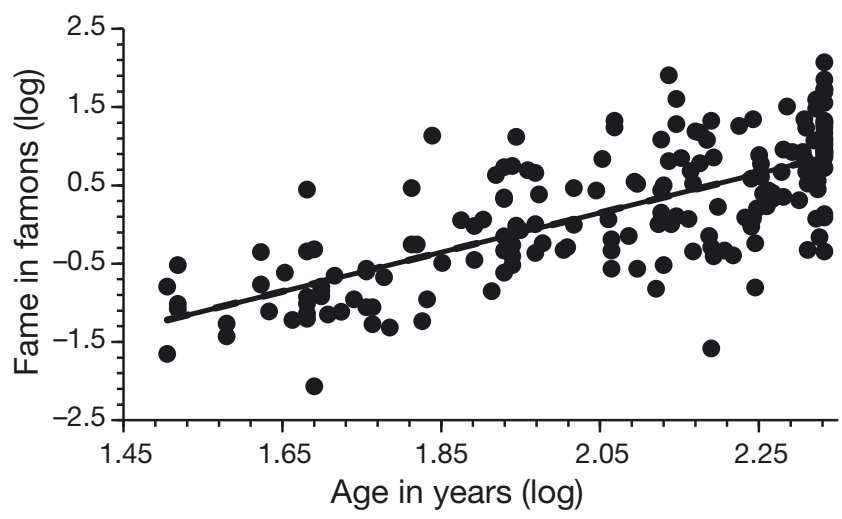

Fig. 6. Relationship $\left(\mathrm{r}^{2}=0.51, \mathrm{n}=181, \mathrm{p}<0.05\right)$ between maximum fame (log) and age of a common name (2015 minus year of first appearance in the books; log) for 181 fish species the highest frequency, 40 to 70 famons, among all species checked between 1800 and 1880 (Figs. 3-5).

Maximum fame in English books was significantly related to the age of the English common names for the 181 common names that had frequencies $>0$ (Fig. 6). In contrast, no relationship was found between $L_{\max }$ and maximum fame (log scale; $\mathrm{r}=0.143$, $\mathrm{n}=181, \mathrm{p}=0.055$ ).

\section{DISCUSSION}

In the present study, Ngram was successfully used for identifying the most famous fish in the Englishspeaking world. Undoubtedly, apart from books there are several other sources (e.g. newspapers, magazines, media, news archives: Leetaru 2011, Michel et al. 2011; blogs and social networks: Dodds et al. 2011, Altmann et al. 2011, Ratkiewicz et al. 2011; Facebook: Schwartz et al. 2013; Scopus, Web of Science, Google Scholar: for determining the most famous fish in the scientific literature, including journals and conference proceedings) that are also important and useful for studying various scientific and cultural aspects, including fame of entities, and which were not considered here.

The results of the Ngram analysis showed that the goldfish is the most famous fish in the English speaking world based on the number of famons. Goldfish is a freshwater species of the family Cyprinidae, which is characterized by a wide phenotypic variability and a global distribution (Froese \& Pauly 2015). It has been a model fish for laboratory experiments (Balon 2004) and is among the most popular aquarium fish species. It was the second fish species to be domesticated after common carp Cyprinus carpio (Balon 2004). It is noteworthy here that despite the fact that Darwin had an apparently small interest in fishes (i.e. only $0.7 \%$ of the total words written by Darwin refer to fishes) he wrote extensively on goldfish; in fact, this is the only fish that was given a section heading (Pauly 2008) in one of his books (Darwin 1868, p. 296297), in which its domestication and variability in color and size are discussed. Goldfish form a monophyletic lineage, with all varieties being derived from one domestication event (Rylková et al. 2010) in China more than $1000 \mathrm{yr}$ ago (i.e. at least since the Song dynasty, 960-1279; Darwin 1868, Smartt 2001), although semi-domestication took place earlier (Smartt 2001). Goldfish appeared in Beijing in 1330, and by 1506-1521 occurred in large numbers outside the Forbidden City; by the late 1540s, keeping goldfish in houses was a popular hobby throughout China (Balon 
2004). By the early 1500s this species was introduced to Japan (Balon 2004), and it was first introduced to Europe in 1611 or 1691 (Mulertt 1883, p. 7) or as early as the 1550s (Darwin 1868), most probably in Portugal from where it spread to Great Britain (in 1691) and other European countries (Mulertt 1883, p. 7). It had become a very popular pet by the 1700s (Brunner 2003) and was so popular in Europe that it was considered as a symbol of good luck and fortune and was offered by husbands to their wives on their first wedding anniversary (Mulertt 1883, Brunner 2003). Although Smartt (2001) mentioned that the earliest record of the introduction of goldfish from Europe to the US dates back to 1874, it was probably introduced earlier, sometime in the 1850s, given that by 1865 it was sold in a New York pet shop and the first hatchery started in Ohio in 1882 (Brunner 2003). Thereafter, it became popular throughout the US (Brunner 2003), a fact that is also reflected in its relative frequency in the English books, which increased exponentially since 1850 (Fig. 3).

Undoubtedly, one expects a famous entity to be the subject of different aspects of human culture. Indeed, goldfish are the protagonists in several movies (e.g. see www.imdb.com/title/tt2555048/), TV series (e.g. 'Being Human', a UK television series), children's literature (e.g. Dr. Seuss's 1957 'The Cat in the Hat', Helen Palmer's 1961 'A Fish Out of Water'), and poems, and are featured in paintings (e.g. see www. artistsandart.org/2009/09/goldfish-in-painting.html), including many by Henri Matisse, and on stamps (see the Appendix). Goldfish are also the subjects of many quotes attributed to celebrities (e.g. Henri Matisse, theoretical physicist Stephen Hawking, Princess Margaret, actor Paul Rudd, and writer Ashwin Sanghi) ${ }^{\mathbf{1}}$. Interestingly, the raising of goldfish by children mod-

\footnotetext{
${ }^{1}$ Celebrity quotes are available at www.brainyquote.com/ quotes/keywords/goldfish.html. Examples listed here include Henri Matisse: 'I wouldn't mind turning into a vermilion goldfish.' Stephen Hawking: 'A few years ago, the city council of Monza, Italy, barred pet owners from keeping goldfish in curved bowls... saying that it is cruel to keep a fish in a bowl with curved sides because, gazing out, the fish would have a distorted view of reality. But how do we know we have the true, undistorted picture of reality?' Princess Margaret: 'I have as much privacy as a goldfish in a bowl.' Paul Rudd: 'I think there's something great and generic about goldfish. They're everybody's first pet.' Ashwin Sanghi: 'The average human attention span was 12 seconds in 2000 and 8 seconds in 2013. A drop of $33 \%$. The scary part is that the attention span of a goldfish was 9 seconds, almost $13 \%$ more than us humans. That's why it's getting tougher by the day to get people to turn the page. Maybe we writers ought to try writing for goldfish!'
}

ifies children's biological interference (i.e. raisers use their knowledge of goldfish to predict and explain the reactions of other aquatic animals; Hatano \& Inagaki 2002). Thus, as Smartt (2001, p. 1) put it '... goldfish could be proclaimed as the Millennium fish!'

Given that fame is relative, one question that arises is how famous goldfish are when compared to other domesticated animals or even humans. For instance, horses and dogs were the only domesticated animals appearing in the top 10 most favorite animals voted in 2004 by more than 50000 viewers (from 73 countries) of the Animal Planet cable and satellite channel (http://news.bbc.co.uk/cbbcnews/hi/newsid_4070000/ newsid_4073100/4073151.stm). The fame of goldfish (maximum 117) is more than 40 times smaller than that of horses (i.e. the word 'horse' displays frequencies that decline from 9000-11000 famons in 18001900 to 4000-5000 in 1960-2000) and dogs (the frequency of the word 'dog' increases from 2300 famons in 1800 to over 4000 famons in 2000). This agrees with the fact that when exploring the relationship of Japanese people with animals, Kudo \& Macer (1999) found that this relationship depends on how familiar they are with a particular species and its perceived function and role. The Japanese were overall more familiar with dogs and cats than with fish (which were mentioned by $3 \%$ of the people interviewed). Both horses and dogs were domesticated many thousands of years before goldfish and played a vital role in human well-being (Balon 2004), with horses having a direct and indirect impact on the US economy of more than $\$ 100$ billion (The American Horse Council 2005). Yet, the fame of goldfish is slightly higher than that of Albert Einstein and Alexander the Great (74-95 and 91-107 famons, respectively, between 1980 and 2000), but lower than those of, e.g. Aristotle and Plato (for both of which frequencies fluctuate around 1500 famons between 1800 and 2000).

The analysis presented here suffers from certain biases with respect to the frequency estimations. Firstly, several species might have more than one common name, a fact affecting their Ngram frequencies. In the present study, the common names in the sources from which the 250 species were extracted matched the FishBase English common names, with the exception of 23 species (Table S1 in the Supplement). For 3 out of the 23 species, either the FishBase or the source common name has other uses in English and thus the corresponding frequencies were not used. For Salmo trutta, the common name in one source is 'brown trout' whereas in FishBase, it is 'sea trout.' Because both common names appear with 
similar, high frequencies, this was the only case in which their frequencies were summed. For the remaining 19 species, the differences in the maximum frequencies between the FishBase and source common names were very small. In 5 cases, both common names had 0 famons, in 9 cases the difference between the frequencies of the 2 common names was $<1$ famon (with all maxima being also $<1$ famon), and in 5 cases the difference was between 1.59 and 6.66 famons (with all maxima being $<6.8$ famons). Thus, this bias does not affect the results with respect to the dominance of goldfish. Secondly, for species having a common name that is a word which also has other uses in the English language (e.g. person names, locations, adjectives, other animal species), sophisticated disambiguation algorithms must probably be used on the downloaded Ngram dataset (see Acerbi et al. 2013) in order to identify the correct frequency of this common name within a conceptual context related to fish. In any case, this bias leads to smaller frequencies for the implicated species and thus does not affect the fame status of goldfish. The above mentioned 2 biases also show the importance of coining a unique common name corresponding to only one organism (e.g. oscar or flier vs. bluefish, goldfish). Thirdly, common names of fish could change over time and this might affect the estimates of relative frequencies. This effect was not examined here. However, the facts that about $60 \%$ of the common names appeared in the English books for the first time between 1800 and 1899 (without excluding the possibility that they had appeared much earlier in English books or books in other languages), and that the frequencies of about $77 \%$ of the common names exhibited long-term increasing trends during the study period both indicate that the effect of such a bias would be minimal. Finally, the potential effect of the relative availability of books was also not examined here.

The present analysis refers to the corpus of English books (and English common names). The corpus of digitized books includes books in many other languages (i.e. Spanish, French, German, Italian, Hebrew, Russian, simplified Chinese), and the results of a similar analysis could be different in these (and other) languages, especially so for languages that were more important than English until recently. It is worth mentioning here, however, that 'goldfish' is not only used as a common name in English-speaking countries but also in several other countries (e.g. Mexico, Russia, Uzbekistan, Austria; Froese \& Pauly 2015). In fact, the word 'goldfish' appears in the corpus of books in other languages with relative frequencies ranging from 3.1 to 67 famons and years of first appearance ranging from 1800 to 1929 depending on the language (i.e. simplified Chinese: first appearance in 1929, maximum 67 famons; French: first appearance in 1800, maximum 7.4 famons; German: first appearance in 1840, maximum 11. 7 famons; Italian: first appearance in 1886, maximum 3.8 famons; Spanish: first appearance in 1876, maximum 3.1 famons). This shows the universality and dominance of goldfish among fishes in the digitized published heritage.

I found that the older a common name is, the greater the fame of that species, irrespective of body size. This indicates that fame is not related to the apparent conspicuousness of a species (e.g. a big fish) but rather to its historical relation to humans. Fish are generally characterized by continually increasing fame, which must be attributed to the fact that fish are there forever and their fame is accumulated through experiences that are shared from generation to generation. The same is also true of university reputations (Stergiou \& Tsikliras 2014). This fame accumulation certainly reflects the continually growing importance of fish to the well-being of humans and agrees with the new common names appearing in the books over time. Linguistically, trends in relative frequencies are also related to the birth and death of words (see Petersen et al. 2012), in this case of common names. Finally, the frequencies of the majority of the fish species examined here are characterized by long-term cycles, which might reflect various events. However, this is outside the scope of this work (but see Gao et al. 2012, for analyzing longrange correlations in Ngram frequencies).

The results of the present study give rise to cultural and conservation implications as well as ethical considerations. The fact that the goldfish is the most famous fish indicates that non-consumptive cultural aspects, including aesthetic, spiritual, educational, and recreational components, play a central role in defining the relationship of humans with other organisms, in this case fish. This agrees with the findings of Kudo \& Macer (1999), who reported that people interviewed on why they like animals ranked the aesthetic/spiritual aspects (i.e. their cuteness or their behavior) very high. It is logical to assume that this also applies to the ecosystems in which these organisms are embedded. Ecosystems provide various services, which generate benefits contributing to human well-being (MEA 2005). Ecosystem services have become important for planning, conservation, decision making, and management, and research on cultural services is growing as a multidisciplinary research field (Chan et al. 2012a,b, Hernández-Mor- 
cillo et al. 2013, Milcu et al. 2013, Satz et al. 2013). The present study shows that ecosystem cultural services and benefits, which are closely associated with the remaining services (Chan et al. 2012a,b), are as important as the provisioning (e.g. food, fresh water), regulating (e.g. climate regulation), and supporting services (e.g. nutrient cycling) (see also Holmlund \& Hammer 1999 for services generated by fish). Yet, despite their importance, cultural services have not yet been adequately integrated within the ecosystem service framework and, with the exception of tourism (Hernández-Morcillo et al. 2013), they are excluded from economic evaluations because there is no commonly accepted framework for doing so, and/or because nonmaterial values cannot be characterized using monetary methods (Chan et al. 2012a,b, Daniel et al. 2012, Hernández-Morcillo et al. 2013, Milcu et al. 2013, Satz et al. 2013). This raises ethical issues related to the recent attempts for ecosystem planning and management based on or using ecosystem services (see also Jax et al. 2013). In fact, there is an 'ethical' need to assess cultural services (Hernández-Morcillo et al. 2013) and to integrate them with other services (Satz et al. 2013). Careful considerations and valuations of cultural services in conservation and management plans will have important synergies with the preservation of the remaining services (Daniel et al. 2012). To that end, new methods, derived from social science (Chan et al. 2012a), and new conceptual approaches should be developed (Milcu et al. 2013), with Ngram being one potential approach. In addition, more effort should be devoted to involving relevant stakeholders through the various phases of decision making (HernándezMorcillo et al. 2013).

Acknowledgements. I thank Drs. Daniel Pauly, Howard I. Browman, Athanassios C. Tsikliras, Darryl Macer, and an anonymous reviewer for useful comments and suggestions.

\section{LITERATURE CITED}

Acerbi A, Lampos V, Garnett P, Bentley RA (2013) The expression of emotions in 20th century books. PLOS ONE 8:e59030

Ahlawat S, Ahlawat S (2013) An innovative decade of enduring accounting ideas as seen through the lens of culturomics: 1900-1910. Am J Bus Res 6(1):63-75

Altmann EG, Pierrehumbert JB, Motter AE (2011) Niche as a determinant of word fate in online groups. PLOS ONE 6:e19009

Balon EK (2004) About the oldest domesticates among fishes. J Fish Biol 65(Suppl A):1-27

Brown C (2015) Fish intelligence, sentience and ethics. Anim Cogn 18:1-17
Brunner B (2003) The ocean at home. Princeton Architectural Press, New York, NY

* Chan KMA, Satterfield T, Goldstein J (2012a) Rethinking ecosystem services to better address and navigate cultural values. Ecol Econ 74:8-18

Chan KMA, Guerry AD, Balvanera P, Klain S and others (2012b) Where are cultural and social in ecosystem services? A framework for constructive engagement. Bioscience 62:744-756

* Cortés E (1999) Standardized diet compositions and trophic levels of sharks. ICES J Mar Sci 56:707-717

Cunnane SC, Crawford MA (2003) Survival of the fattest: fat babies were the key to evolution of the large human brain. Comp Biochem Physiol A Mol Integr Physiol 136: $17-26$

*Daniel TC, Muharet A, Arnberger A, Aznar O and others (2012) Contributions of cultural services to the ecosystem services agenda. Proc Natl Acad Sci USA 109: 8812-8819

Darwin C (1868) The variation of animals and plants under domestication, Vol I. John Murray, London

Davidson JN (1997) Courtesans and fishcakes: the consuming passions of classical Athens. The University of Chicago Press, Chicago, IL

Diller HJ (2013) Culturomics and genre: wrath and anger in the 17th century. In: McConchie RW, Juvonen T, Kaunisto M, Nevala M, Tyrkkö J (eds) Selected Proceedings of the 2012 Symposium on New Approaches in English Historical Lexis (HEL-LEX 3). Cascadilla Proceedings Project, Somerville, MA, p 54-65. www.lingref.com/cpp/ hel-lex/2012/paper2836.pdf (accessed on 17 November 2015)

ํ.Dodds PS, Harris KD, Kloumann IM, Bliss CA, Danforth CM (2011) Temporal patterns of happiness and information in a global social network: hedonometrics and Twitter. PLOS ONE 6:e26752

Egerton FN (2001) A history of the ecological sciences, Part 3. Hellenistic natural history. Bull Ecol Soc Am 82: 201-205

Egnal M (2013) Evolution of the novel in the United States the statistical evidence. Soc Sci Hist 37:231-254

Froese R, Pauly D (eds) (2015) FishBase. www.fishbase.org (accessed on 25 October 2015)

Gao J, Hu J, Mao X, Perc M (2012) Culturomics meets random fractal theory: insights into long-range correlations of social and natural phenomena over the past two centuries. J R Soc Interface 9:1956-1964

Greenberg P (2010) Four fish. The Penguin Press, New York, NY

* Gruen L (2014) The moral status of animals. In: Zalta EN (ed) The Stanford encyclopedia of philosophy (Fall 2014 edn). https://plato.stanford.edu/archives/fall2014/ entries/moral-animal/ (accessed on 15 December 2016)

Hatano G, Inagaki K (2002) Young children's naïve thinking about the biological world. Psychology Press, New York, NY

*Hernández-Morcillo M, Plieninger T, Bieling C (2013) An empirical review of cultural ecosystem service indicators. Ecol Indic 29:434-444

*Holmlund CM, Hammer M (1999) Ecosystem services generated by fish populations. Ecol Econ 29:253-268

Jax K, Barton DN, Chan KMA, de Groot R and others (2013) Ecosystem services and ethics. Ecol Econ 93:260-268

Kudo R, Macer D (1999) Relationships towards animals in Japan. Eubios J Asian Int Bioeth 9:135-137 
Kurlansky M (1998) Cod: a biography of the fish that changed the world. Penguin Books, New York, NY

KLeetaru K (2011) Culturomics 2.0: forecasting large-scale human behavior using global news media tone in time and space. First Monday 16: doi:10.5210/fm.v16i9.3663. www.firstmonday.dk/ojs/index.php/fm/article/view/3663

Libralato S, Pranovi F, Stergiou KI, Link JS (2014) Trophodynamics in marine ecology: 70 years after Lindeman. Mar Ecol Prog Ser 512:1-7

Lin Y, Michel JB, Aiden EL, Orwant J, Brockman W, Petrov S (2012) Syntactic annotations for the Google Books Ngram corpus. Proceedings of the 50th Annual Meeting of the Association for Computational Linguistics, Jeju, Republic of Korea, 8-14 July 2012, p 169-174 https:// aclweb.org/anthology/P/P12/P12-3029.pdf (accessed on 17 November 2015)

McEvoy A (1986) The fisherman's problem: ecology and law in the California fisheries, 1850-1980. Cambridge University Press, New York, NY

MEA (Millennium Ecosystem Assessment) (2005) Ecosystems and human well-being: synthesis. Island Press, Washington, DC

Merchant C (1997) Fish first! The changing ethics of ecosystem management. Hum Ecol Rev 4:25-30

Michel JB, Shen YK, Aiden AP, Veres A and others (2011) Quantitative analysis of culture using millions of digitized books. Science 331:176-182

Milcu AI, Hanspach J, Abson D, Fischer J (2013) Cultural ecosystem services: a literature review and prospects for future research. Ecol Soc 18:44

Mohammad S (2011) From once upon a time to happily ever after: tracking emotions in novels and fairy tales. Proceedings of the 5th ACL-HLT Workshop on Language Technology for Cultural Heritage, Social Sciences, and Humanities, Portland, OR, p 105-114. https://www. aclweb.org/anthology/W/W11/W11-1514.pdf (accessed on 17 November 2015)

Montagne M, Morgan M (2013) Drugs on the internet, Part IV: Google's Ngram Viewer analytic tool applied to drug literature. Subst Use Misuse 48:415-419

Mulertt H (1883) The goldfish and its systematic culture with a view to profit. Hugo Mulertt, Brooklyn, NY. http:// chestofbooks.com/animals/aquaria/Goldfish-Culture/\#. VddTCOQViL9 (accessed on 17 November 2015)

Nazar R, Renau I (2012) Google books N-gram corpus used as a grammar checker. Proceedings of the EACL 2012 Workshop on Computational Linguistics and Writing, Avignon, France, April 23, 2012, p 27-34. www.aclweb. org/anthology/W12-0304 (accessed on 17 November 2015)

Pauly D (2008) Darwin's fishes: an encyclopedia of ichthyology, ecology, and evolution. Cambridge University Press, Cambridge

Pauly D, Stergiou KI (2014) The ethics of human impacts and the future of the earth's ecosystems: introduction. Ethics Sci Environ Polit 14:1-5

Pauly D, Christensen V, Dalsgaard J, Froese R, Torres F Jr (1998) Fishing down marine food webs. Science 279: 860-863

Petersen AM, Tenenbaum J, Havlin S, Stanley HE (2012) Statistical laws governing fluctuations in word use from word birth to word death. Sci Rep 2:313
Ratkiewicz J, Conover MD, Meiss M, Goncalves B, Flammini A, Menczer F (2011) Detecting and tracking political abuse in social media. Proceedings of the 5th International AAAI Conference on Weblogs and Social Media. Association for the Advancement of Artificial Intelligence, Palo Alto, CA, p 297-304. www.aaai.org/ocs/index. php/ICWSM/ICWSM11/paper/view/2850 (accessed on 17 November 2015)

Kavallion M (2011) The two poverty enlightenments: historical insights from digitized books spanning three centuries. Poverty Public Policy 3:1-46

* Reis LC, Hibbeln JR (2006) Cultural symbolism of fish and the psychotropic properties of omega-3 fatty acids. Prostaglandins Leukot Essent Fatty Acids 75:227-236

* Rylková K, Kalous L, Šlechtová V, Bohlen J (2010) Many branches, one root: first evidence for a monophyly of the morphologically highly diverse goldfish (Carassius auratus). Aquaculture 302:36-41

Satz D, Gould RK, Chan KMA, Guerry A and others (2013) The challenges of incorporating cultural ecosystem services into environmental assessment. Ambio 42:675-684

* Schwartz HA, Eichstaedt JC, Kern ML, Dziurzynski L and others (2013) Personality, gender, and age in the language of social media: the open-vocabulary approach. PLOS ONE 8:e73791

Smartt J (2001) Goldfish varieties and genetics: a handbook for breeders. Blackwell Science, Oxford

Soper DS, Turel O (2012) An n-Gram analysis of communications 2000-2010. Commun ACM 55:81-87 (ACM)

Stergiou KI (2005) FishBase Symposium: fish and more. In: Stergiou KI, Bobori D (eds) Fish and more: $3^{\text {rd }}$ FishBase Mini Symposium. Aristotle University of Thessaloniki, University Studio Press, Thessaloniki, p 1-4

Stergiou KI (2011) Mediterranean ecosystems, shifting baselines and databases. In: Gertwagen R, Fortibuoni T, Giovanardi $\mathrm{O}$, Libralato $\mathrm{S}$, Solidoro $\mathrm{C}$, Raicevich S (eds) When humanities meet ecology: historic changes in Mediterranean and Black Sea marine biodiversity and ecosystems since the Roman period until nowadays. Languages, methodologies and perspectives. ISPRA, Serie Atti, Rome, p 95-102

Stergiou KI, Karpouzi VS (2002) Feeding habits and trophic levels of Mediterranean fish. Rev Fish Biol Fish 11:217-254

Stergiou KI, Tsikliras AC (2014) Global university reputation and rankings: insights from culturomics. Ethics Sci Environ Polit 13:193-202

* Sumaila UR, Stergiou KI (2015) Economics of marine conservation. Mar Ecol Prog Ser 530:179-182

The American Horse Council (2005) Most comprehensive horse study ever reveals a nearly $\$ 40$ billion impact on the U.S. Economy. American Horse Council. www. manesandtailsorganization.org/American_Horse_Council _2005_Report.pdf (accessed on 17 November 2015)

Twenge JM, Campbell WK, Gentile B (2012) Male and female pronoun use in U.S. books reflects women's status, 1900-2008. Sex Roles 67:488-493

Twenge JM, Campbell WK, Gentile B (2013) Changes in pronoun use in American books and the rise of individualism, 1960-2008. J Cross Cult Psychol 44:406-415

*Vasilakopoulos P, Maravelias CD, Tserpes G (2014) The alarming decline of Mediterranean fish stocks. Curr Biol 24:1643-1648 
Appendix. Examples of the use of goldfish Carassius auratus in artistic representations

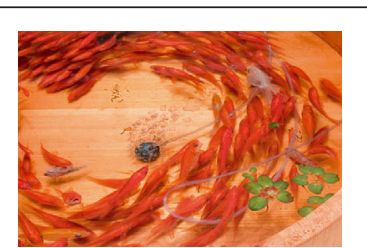

\section{Riusuke Fukahori}

Three dimensional images of goldfish using acrylic paint over clear resin

http://www.boredpanda.com/realistic-3d-goldfish-paintings-riusuke-fukahori/

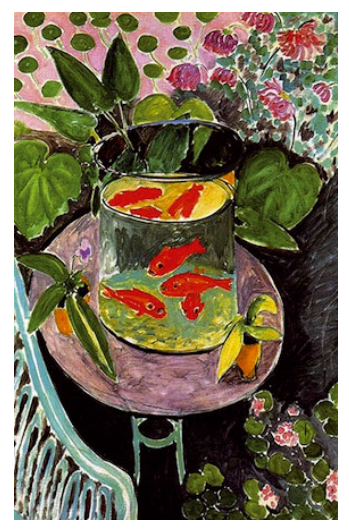

\section{Henri Matisse}

'Goldfish', 1912, oil on canvas (Pushkin Museum of Art, Moscow)

https://www.khanacademy.org/humanities/art-1010/early-abstraction/fauvismmatisse/a/matisse-goldfish

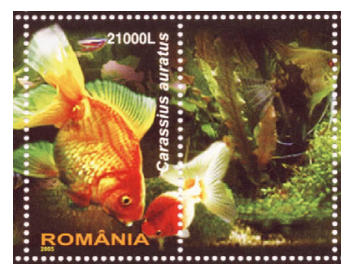

FishBase lists 50 stamps from 12 countries

http://www.fishbase.org/photos/SpeciesStampsList.php?speccode $=271 \& \operatorname{SortBy}=\mathrm{G}$ enus\&image $=$ on

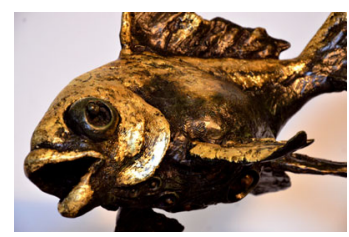

Stephen Rautenbach

'Liberation of the Goldfish'

https://stephenrautenbach.com/2015/05/17/goldfish-sculpture-in-bronze/

Editorial responsibility: Darryl Macer, Prakanon, Bangkok, Thailand
Submitted: May 19, 2016; Accepted: February 14, 2017 Proofs received from author(s): April 28, 2017 